\title{
O afastamento do trabalho por afeç̧ões lombares: repercussões no cotidiano de vida dos sujeitos
}

\section{The retirement of work from low back diseases: repercussions on the subjects daily lifes}

\author{
Maria do Carmo Baracho de Alencar ${ }^{1}$, \\ Tathiane Mye Terada²
}

\begin{abstract}
ALENCAR, M. C. B.; TERADA, T. M. O afastamento do trabalho por afecções lombares: repercussões no cotidiano de vida dos sujeitos. Rev. Ter. Ocup. Univ. São Paulo, v. 23, n. 1, p. 44-51, jan./abr. 2012.

RESUMO: O objetivo deste estudo foi investigar sobre o afastamento do trabalho por afecções lombares de sujeitos atendidos em estágio do curso de Terapia Ocupacional da Universidade Federal de São Paulo, e as consequências no cotidiano de vida. Foi utilizado instrumental contendo dados demográficos, relacionados ao trabalho, aspectos clínicos, o quanto a dor afetou o cotidiano de vida, entre outros, e o Health Assessment Questionnaire - HAQ, aplicados sob forma de entrevista. Participaram do estudo oito $(\mathrm{n}=8)$ sujeitos com idade entre 37 e 55 anos, sendo quatro de cada gênero. Todos referiram dores crônicas em região lombar, entre outras. $\mathrm{O}$ afastamento do trabalho e a dor prejudicaram diversos aspectos do cotidiano de vida dos sujeitos, e este artigo reforça a necessidade de um olhar mais abrangente sobre a incapacidade.
\end{abstract}

DESCRITORES: Licença médica; Dor crônica; Terapia ocupacional, Atividades cotidianas.

\footnotetext{
1. Docente do Departamento de Gestão e Cuidados em Saúde da Universidade Federal de São Paulo, Instituto Saúde e Sociedade.

2. Terapeuta Ocupacional, formada pelo curso de Terapia Ocupacional da Universidade Federal de São Paulo.

Endereço para correspondência: Docente do Departamento de Gestão e Cuidados em Saúde da Universidade Federal de São Paulo, Instituto Saúde e Sociedade. Rua Professor Torres Homem, 675 ap 72 Santos SP CEP: 11025-021. e-mail: belinha.alecar1@gmail.com
} 


\section{INTRODUÇÃO}

$\mathrm{O}$ trabalhador pode vir a se afastar do trabalho por diversos motivos (gestação, doença de familiar, lesão em desporte, entre outros) ou por acidentes do trabalho, que podem ser classificados como: acidentes típicos, acidentes de trajeto, doenças profissionais e as doenças do trabalho. De acordo com a Previdência Social (2009), acidente típico é caracterizado por acidentes decorrentes da característica da atividade profissional desempenhada pelo acidentado; acidente de trajeto é considerado como acidentes ocorridos no trajeto entre a residência e o local de trabalho do segurado e vice-versa; doença profissional é aquela produzida ou desencadeada pelo exercício do trabalho peculiar a determinado ramo de atividade; e as doenças do trabalho aquelas adquiridas ou desencadeadas em função de condições especiais em que o trabalho é executado. Em caso de acidente de trabalho, deve ser registrada a Comunicação de Acidente de Trabalho - CAT, regulamentada pelo Decreto n².172/97. A Previdência Social (2009) ressalta a importância dessa comunicação, tendo em vista as informações nela contidas, não somente pelo ponto de vista previdenciário, estatístico e epidemiológico, mas também trabalhista e social.

Entre os acidentes e doenças do trabalho, a região lombar é comumente acometida. Segundo o Anuário Estatístico de Acidente de Trabalho (MPAS, 2009), foram registrados no Brasil em 2009, 46.608 casos de Dorsalgias (M54), segundo a Classificação Internacional de DoençasCID-10, estando em terceiro lugar entre os registros. Meziat Filho e Silva (2011) citam que a dor nas costas idiopática foi a primeira causa de invalidez e de auxílio-doença no Brasil em 2007, e que o diagnóstico de Dorsalgia apresentou talvez frequência elevada, pela não especificação do local de dor. As dorsalgias englobam cervicalgias, dores torácicas, entre outras, além das dores lombares (lombalgias). Em estudo de Picoloto e Silveira (2008) em relação aos afastamentos do trabalho, a região lombar apresentou a maior ocorrência.

O afastamento do trabalhador é caracterizado pela incapacidade ou redução da capacidade, funcionalidade e performance no trabalho (WADELL, 2006). Para Mângia et al. (2008) o problema de incapacidade tem relevância social e econômica e várias modalidades contribuem para este quadro, entre elas os acidentes de trabalho. $\mathrm{O}$ afastamento do trabalho pode levar a demissões ou à dificuldade de reingresso no mercado de trabalho, e esse fato acaba gerando comprometimentos no convívio familiar, com repercussões financeiras, desestabilizando o núcleo de convivência, entre outros (GAEDKE; KRUG, 2008).

As afecções em região lombar têm entre os sintomas a dor, e de acordo com a duração, os episódios podem ser agudos ou crônicos. A dor aguda geralmente ocorre na fase inicial da doença, e é mais localizada, tem causa geralmente definida, entre outros; enquanto a dor crônica é definida como aquela que persiste além do tempo esperado para resolução clínica que provocou a sua ocorrência, e gera incapacidade para as atividades profissionais, sociais e familiares (YENG et al., 2007).

Para a proposta deste artigo, foi preciso deixar de lado a abordagem biológica da doença, e tentar entender os significados e representações envolvidas nos processos de doença-afastamento-saúde. É importante tentar compreender as experiências, vivências, dificuldades e expectativas dos sujeitos, entre outros. O afastamento do trabalho pode levar ao desgaste e sofrimento do trabalhador, que se encontra muitas vezes impossibilitado de desempenhar adequadamente seus papéis sociais e funções da vida cotidiana que realizava anteriormente ao adoecimento e afastamento. Papel social é a promulgação de direitos e deveres ligados a uma determinada situação social, ou seja, quando um ator assume um papel social estabelecido geralmente verifica que uma fachada já foi estabelecida para este papel, determinada entre outros, por aspectos culturais (GOFFMAN, 2009). A ruptura do trabalho, leva ao afastamento do trabalhador de um lugar por ele conquistado: poder aquisitivo, relações sociais, entre outros (RAMOS et al., 2008).

A situação de afastamento não é vista pelos membros da família como temporária para tratar de uma doença adquirida no trabalho, é vista na maioria das vezes, como "desocupação", situação carregada de valores negativos (BRASIL, 2001). O trabalho proporciona uma inserção social do indivíduo, pois o cidadão quando está trabalhando é considerado em geral produtivo, eficiente, entre outros. Além disso, ter saúde suficiente ou mínima para se trabalhar é uma exigência do mercado de trabalho, e em sistema capitalista de produção espera-se que a força de trabalho possa garantir a produtividade esperada. Para Merlo et al. (2001) os indivíduos afastados do trabalho em geral expressam sentimentos de desvalia, insegurança quanto ao futuro profissional, incerteza e morosidade no processo terapêutico e reabilitação, medos e fantasias inconscientes, manifestações depressivas e de revolta, entre outras.

Conforme os diagnósticos, eficácia ou não dos tratamentos clínicos, os trabalhadores afastados acometidos por afecções lombares, podem ter dores crônicas, mais especificamente: lombalgia e/ou lombociatalgia crônica. A dor crônica segundo Yeng et al. (2007) caracteriza-se por ocorrência de ansiedade, hostilidade, período de inatividade, entre outros, com consequências financeiras e sociais. A dor 
é uma experiência corporal prévia que agrega significados psíquicos e culturais (SARTI, 2011). Em casos de cronicidade e incapacidade há extensa evidência clínica que as condições de saúde dependem de aspectos psicossociais (WADELL, 2006). Sujeitos com dores crônicas podem apresentar sintomas depressivos, principalmente aqueles que tiveram suas vidas alteradas por suas incapacidades de funcionar socialmente, com dificuldades em suas atividades diárias (GAEDKE; KRUG, 2008).

O objetivo deste estudo foi investigar sobre o afastamento do trabalho por afeç̧ões lombares de sujeitos atendidos em estágio profissionalizante do curso de Terapia Ocupacional, e as consequências no cotidiano de vida.

\section{MATERIAIS E MÉTODOS}

O estudo teve caráter exploratório e descritivo. Foram selecionados sujeitos afastados do trabalho por afeç̧ões lombares, que foram atendidos em estágio profissionalizante de Terapia Ocupacional na área de Saúde e Trabalho, da Universidade Federal de São Paulo, Campus da Baixada Santista, no ano de 2009. O critério de seleção foi de serem trabalhadores afastados do trabalho por afecções lombares, de ambos os gêneros, e podendo ou não apresentar outros diagnósticos clínicos. A seleção ocorreu através de análises de registros efetuados na época.

Foi realizado um contato telefônico pela professora responsável junto aos sujeitos selecionados para participarem do estudo. Foi aplicado um instrumental (questionário), aplicado sob a forma de entrevista junto a esses trabalhadores, que continha os seguintes dados: nome, idade, gênero, estado civil, se tinha filhos, escolaridade, diagnóstico clínico, última profissão, causa do adoecimento, tempo de afastamento, início dos sintomas, outros dados clínicos, uso de medicamentos, tratamentos realizados, sobre o quanto a dor afetava o cotidiano de vida em diversos aspectos: lazer, afazeres domésticos, atividades sociais com amigos, entre outras. Algumas questões tiveram respostas com as percepções dos sujeitos registradas, de modo descritivo tal como foi expresso, e em papel e caneta. Ainda, o Instrumento Health Assesment Questionnaire - HAQ (Ferraz et al., 1990) que é um instrumento que investiga sobre atividades de vida diária, como: vestir-se, levantar-se, entre outras. A escolha deste instrumento se deu pelo fato dos sujeitos relatarem sintomas dolorosos ou de desconforto em outras regiões corporais, além da região lombar.

O projeto foi aprovado pelo Comitê de Ética em Pesquisa da Universidade Federal de São Paulo (CEP: 0534/10), em 30 de abril de 2010.

\section{RESULTADOS E DISCUSSÃO}

Do total de cinquenta e quatro $(\mathrm{n}=54)$ sujeitos atendidos em estágio do curso de Terapia Ocupacional da Universidade Federal de São Paulo no ano de 2009, dentre eles trabalhadores afastados e não afastados do trabalho, oito $(n=8)$ estavam afastados do trabalho por afecções em região lombar.

Participaram deste estudo oito $(n=8)$ sujeitos trabalhadores afastados do trabalho, faixa etária entre 37 e 55 anos, sendo sete $(\mathrm{n}=7)$ casados e com filhos. Somente dois $(\mathrm{n}=2)$ sujeitos tinham o segundo grau completo e os demais tinham o primeiro grau entre completo e incompleto. Todos com diagnóstico clínico de protusão/hérnia discal lombar, entre outros. Segundo Negrelli (2001) a etiologia da hérnia discal é multifatorial, e dentre os aspectos envolvidos estão: a flexão do tronco por períodos prolongados aliados ao esforço físico, carregar ou levantar pesos, posturas inadequadas, envelhecimento, entre outros. Mais da metade dos entrevistados estava afastado do trabalho há mais de dois anos, e vivenciando uma rotina de consultas médicas, exames, tratamentos e perícias do Instituto de Seguridade Social INSS. Indivíduos afastados do trabalho passam por situações desagradáveis de descaso da doença junto aos peritos, gerando desgaste e sofrimento (ALENCAR; OTA, 2010).

As funções dos entrevistados foram variadas: auxiliar de serviços gerais $(n=4)$, eletricista $(n=1)$, cortadeira $(\mathrm{n}=1)$, cozinheira $(\mathrm{n}=1)$ e auxiliar de limpeza $(\mathrm{n}=1)$, e todos trabalhavam nessas funções há mais de cinco anos. Sete $(n=7)$ não tinham se submetido à cirurgia, e um $(n=1)$ tinha se submetido. Quanto aos tratamentos ou intervenções que estavam realizando, três $(\mathrm{n}=3)$ continuavam participando das intervenções da Terapia Ocupacional em 2010, dois $(n=2)$ com Acupuntura, cinco $(n=5)$ com Fisioterapia, um $(n=1)$ era praticante de ginástica, havendo mais de um tratamento ou intervenção sendo realizados por alguns.

Quanto às queixas de dores, todos $(\mathrm{n}=8)$ queixaramse delas no ato da entrevista, sendo as regiões: três $(n=3)$ na coluna em regiões lombar e cervical, três $(\mathrm{n}=3)$ na coluna lombar e coxa, e dois $(n=2)$ na coluna lombar e ombros, e as dores ocorriam com frequência desde o afastamento. Cinco $(n=5)$ faziam uso frequente de medicamentos para o alívio da dor e relataram estarem com sintomas depressivos; destes, três $(n=3)$ eram do gênero feminino e dois $(n=2)$ do gênero masculino.

\section{afastamento}

Aspectos gerais relacionados ao adoecimento $e$

Houve para alguns o descaso de supervisores em 
relação ao acidente ou às dores, sem muita atenção para a situação quando informada, como nos relatos:

"Cai de uma altura de dois metros e tive muita dor nas costas, me mandaram tomar uma injeção e voltar a trabalhar!" (gênero masculino, 48 anos, auxiliar de serviços gerais);

"Eu tinha que trabalhar agachado ou deitado, doía as minhas costas, mas não podia parar" (gênero masculino, 42 anos, eletricista).

A dor é um sinal de alerta, deve ser dado atenção aos sinais e sintomas dos trabalhadores, em todas as situações. Merlo et al. (2003) citam que muitas vezes esse trabalhador se queixa no trabalho e não é levado em consideração sua queixa, por ser um sofrimento “invisível”, e ainda promover um estereótipo de querer fazer um “corpo mole”, de não querer trabalhar. O trabalhador muitas vezes só se dá conta de que está adoecendo ou adoeceu, quando há um descompasso entre as exigências do trabalho e a realizada pelo seu corpo.

Outros relatos obtidos tiveram relações com aspectos da organização do trabalho, como:

“Eu tinha que fazer limpeza do prédio sozinha, era muita coisa para um funcionário só! ” (gênero feminino, 40 anos, auxiliar de limpeza).

“(..) eu era a única para cortar todo o tecido, enquanto tinha seis para costurar.." (gênero feminino, 50 anos, cortadeira).

Havia para alguns trabalhadores exigências elevadas de trabalho e poucos funcionários para as tarefas, além de outros aspectos que geravam desgaste no trabalho. Dependendo das exigências e condições de trabalho, o trabalhador pode vir a executar as tarefas além de suas capacidades físicas, ocasionando riscos à saúde física e mental. No contexto contemporâneo as características de intensificação do trabalho e predomínio de visão de diminuição de custos, contribuem fortemente com o aumento de agravos à saúde, e requer mudanças (ALENCAR; OTA, 2011).

\section{A dor e aspectos do cotidiano de vida dos sujeitos}

Pelo instrumento HAQ, os entrevistados apresentaram dificuldades na realização de algumas atividades de vida diária (básicas e instrumentais). A Tabela 1 abaixo mostra as principais dificuldades encontradas junto aos sujeitos $(n=8)$.

Tabela 1. Principais dificuldades nas atividades de vida diária, pelo Instrumento $H A Q$

\begin{tabular}{l|c|c|c}
\hline $\begin{array}{l}\text { Aspectos analisados e mais relevantes para os casos } \\
\text { de afeç̃óes lombares com dores (n=8) }\end{array}$ & $\begin{array}{c}\text { Sem qualquer } \\
\text { dificuldade }\end{array}$ & $\begin{array}{c}\text { Com alguma } \\
\text { dificuldade }\end{array}$ & $\begin{array}{c}\text { Com muita } \\
\text { dificuldade }\end{array}$ \\
\hline Vestir-se, inclusive amarrar os cordões dos sapatos & 2 & 2 & 4 \\
\hline $\begin{array}{l}\text { Levantar-se de maneira ereta de uma cadeira de encosto } \\
\text { reto e sem braços }\end{array}$ & 1 & 3 & 4 \\
\hline Sentar-se e levantar-se de um vaso sanitário & 1 & 3 & 4 \\
\hline Tomar banho de chuveiro & 2 & 4 & 2 \\
\hline Curvar-se para pegar suas roupas no chão & 0 & 1 & 7 \\
\hline Fazer compras nas redondezas onde mora & 0 & 2 & 6 \\
\hline Entrar e sair de um ônibus & 0 & 2 & 6 \\
\hline Caminhar em lugares planos & 4 & 0 & 4 \\
\hline Deitar-se e levantar-se da cama & 2 & 2 & 4 \\
\hline
\end{tabular}

$\mathrm{Na}$ Tabela 1 acima, as principais dificuldades relacionadas às afecções lombares e entre os entrevistados foram em: vestir-se, levantar-se de maneira ereta de uma cadeira sem os braços, curvar-se para pegar roupas no chão, fazer compras nas redondezas onde mora, entrar e sair de um ônibus, entre outras, afetando o cotidiano de vida dos sujeitos. Polizetti e Leite (2010) citam que a dor requer adaptações até para vestir a roupa, calçar sapatos, além de 
afetar o caminhar, e os sujeitos acabam adotando posturas que defendam o corpo da dor.

Em relação às questões sobre o quanto a dor afetou o cotidiano de vida (do outro Instrumental utilizado), sete $(n=7)$ sujeitos responderam que a dor afetou os afazeres domésticos, deixando de realizar algumas ou grande parte das tarefas, como por exemplo, varrer a casa, limpar a casa, fazer compras. Apenas um trabalhador, do gênero masculino disse que em relação a este aspecto, melhorou após a cirurgia, voltando a realizar tarefas que anteriormente não conseguia. Os demais, principalmente do gênero feminino relataram dificuldades por não terem para quem pedir ajuda no momento necessário, tendendo a fazer as tarefas sozinhas e posteriormente sentiam dores. Alguns relatos registrados expressaram essas dificuldades, como:

"Depois de limpar a casa dói as costas, o ombro, mas não tem ninguém para ajudar.."(gênero feminino, 52 anos, auxiliar de serviços gerais).

"Tenho muita dificuldade para varrer, arrumar a cama.. nem sempre tenho ajuda"(gênero feminino, 40 anos, auxiliar de limpeza).

Vários aspectos podem estar relacionados a essas dificuldades, os filhos podem ser pequenos e não serem capazes de ajudar, os demais membros da família trabalharem e não estarem em casa no momento necessário para ajudar, elas não se sentirem à vontade de solicitar ajuda, entre outros. No caso das mulheres, Ghisleni e Merlo (2005) citam que muitas são chefes da família, responsáveis pelo sustento da casa e criação dos filhos, e mesmo depois de afastadas do trabalho, elas mantêm as responsabilidades em geral pelos afazeres domésticos havendo dificuldades de se desligarem desses afazeres. O fato de ter que realizálos mesmo sabendo que podem desencadear dores, pode gerar desgaste e sofrimento, especialmente se houver talvez conflitos na busca de padrões anteriormente estabelecidos (antes do adoecimento). Em estudo de Polizetti e Leite (2010), as autoras refletem sobre as transformações no papel da mulher na sociedade e uma mulher que trabalha auxiliando ou mantendo o sustento da casa, precisa também desempenhar seu papel de mãe, esposa, filha, que cuida de casa, e não se queixa, não é "mole".

Para alguns homens, a situação também gerava aparentemente algum desgaste, pois também apresentavam limitações em relação aos afazeres domésticos, como no relato:

"Só consigo secar a louça e segurar a mangueira para minha esposa lavar o quintal" (gênero masculino, 42 anos, eletricista).

"Não tenho feito nada, não dá para fazer" (gênero masculino, 44 anos, auxiliar de serviços gerais).
Há necessidade de se passar pelos processos de enfrentamento da situação e adaptação frente às novas condições, que podem ser provisórias ou permanentes. A incapacidade funcional requer entre outros, a necessidade de apoio social, e a família pode exercer um papel fundamental. Em relação aos determinantes para a função e saúde, a importância do modelo biopsicossocial é por este incluir as dimensões biológicas, psicológicas e sociais, e que forma a base da Classificação Internacional de Funcionalidade, Incapacidade e Saúde - CIF (WADELL, 2006; MÂNGIA et al., 2008). Deste modelo biopsicossocial, a parte "bio" envolve o gerenciamento da condição de saúde diretamente através do controle dos sintomas e melhoria nas funções, a parte "psico" envolve o alívio relacionado ao distress e modificações nas crenças sobre as incapacidades, e a "social" envolve a minimização do contexto que envolve a doença (WADELL, 2006). A nova Classificação busca superar o modelo biomédico e a tendência dos modelos tradicionais de reabilitação, de considerar a incapacidade de forma redutiva e centrada na pessoa (MÂNGIA et al., 2008).

Em relação às atividades de lazer, na vida adulta, estas podem ser individuais e/ou grupais, podendo ser diversas. No lazer, alguns deixaram de realizar atividades desportivas, que gostavam, sendo demonstrado em alguns relatos:

"A coisa que mais gostava de fazer era jogar futebol, e agora não posso mais.." (gênero masculino,42 anos, eletricista)

"Não posso mais andar de bicicleta, dói as costas.." (gênero masculino, 44 anos, auxiliar de serviços gerais)

Há em geral um "estranhamento" dos corpos, o "eu” de antes e após o adoecimento com comparações, e que muitas vezes geram sofrimento. E entre as representações que dão sentido ao sofrimento está o desengano quanto à possibilidade de melhora (NEVES; NUNES, 2009). Novas opções de lazer podem ser descobertas e que não exijam impactos sobre a coluna vertebral. O sujeito precisa estar disposto a adaptar-se e às mudanças, e a buscar tratamentos ou intervenções que o auxiliem tanto para o enfrentamento da situação, quanto para o restabelecimento de suas funções, e o Terapeuta Ocupacional pode auxiliá-lo. Não entrando em discussão aqui neste estudo, questões sobre os diversos aspectos que o levaram ao afastamento do trabalho e seus direitos.

Em relação às outras atividades sociais, referindo-se a encontros ou eventos externos com amigos, a dor interferiu em alguns aspectos, como nos relatos:

"Quando saio fico a maior parte do tempo sentado" 
(gênero masculino, 37 anos, auxiliar de serviços gerais);

"Não tenho vontade de sair com amigos, se saio volto logo para casa" (gênero feminino, 40 anos, auxiliar de limpeza).

Pode haver um desgaste relacionado às questões físicas e psíquicas ao sair com amigos. De acordo com Gaedke e Krug (2008), ocorrem mudanças significativas no convívio social após o adoecimento, diminuindo a quantidade de atividades de lazer, em virtude das incapacidades físicas e/ou emocionais.

Para alguns a dor estava causando um desânimo "total" para atividades que seriam prazerosas, como nos relatos:

"Não tenho vontade de fazer mais nada..." (gênero masculino, 42 anos, eletricista).

"Não tenho vontade de sair de casa, nem de assistir televisão..." (gênero masculino, 48 anos, auxiliar de serviços gerais).

Na lombalgia crônica, a incapacidade funcional faz com que os doentes sintam dificuldades de realizar as atividades, tendo muitas vezes que se movimentar de modo lento e cuidadoso, o que faz com que queiram ficar em casa na maior parte do tempo (WEINER et al., 2004). Para os autores ainda, esta incapacidade conduz a um maior isolamento social e falta de atividades agradáveis. O sentimento de inutilidade/ociosidade, além da convivência diária com a dor e dependência de medicação acabam gerando um quadro depressivo (GAEDKE; KRUG, 2008).

Todo ato humano possui em si significação, e os indivíduos só constroem o significado de suas experiências (inclusive da dor), mediante referências coletivas (SARTRI, 2001). Sob este aspecto, poderia se pensar sobre o que representaria na sociedade um indivíduo afastado do trabalho, dentro de um papel social de "doente", ir a eventos sociais e buscar alguma forma de diversão? Se em estudo de Alencar e Ota (2010) um trabalhador refere em relação à perícia, que para se afastar é preciso parecer que está "morrendo". Há necessidade de se refletir sobre essas questões, uma vez que todos têm direito à diversão, inclusive para benefícios à própria saúde. O quanto as representações sociais podem influenciar nas atividades desses sujeitos, e o quanto isso não ocasionaria o agravamento à saúde?

Alguns homens relataram prejuízos em atividades sexuais, como nos relatos:

"Não consigo mais transar com minha mulher direito (...)" (gênero masculino, 42 anos, eletricista).

"Minha mulher pensa que eu tenho outra..." (Gênero masculino, 37 anos, auxiliar de serviços gerais).

O coito envolve muitas vezes o movimento pélvico, e os homens com lombalgia e/ou lombociatalgia crônica podem referir dores durante ou ao final do ato sexual, gerando desconforto e talvez sofrimento. Este fato pode também afetar o interesse pelo ato sexual e gerar conflitos em aspectos relacionados ao papel de marido, e até mesmo de homem em relação à masculinidade e sexualidade. Polizetti e Leite (2010) relatam que tal dor não proporciona sinais visíveis para que as pessoas possam caracterizar a existência de sofrimento (ex.: um membro engessado).

Quanto ao trabalho, todos relataram estarem incapacitados de realizar as tarefas que anteriormente realizavam, especialmente em relação às exigências do trabalho, que não eram somente físicas.

\section{CONSIDERAÇÕES FINAIS}

Verificaram-se neste estudo alguns aspectos relacionados ao afastamento do trabalho por afecções em região lombar, e as repercussões no cotidiano de vida dos sujeitos. Entre os aspectos encontrados: dificuldades em vestir-se, levantar-se de maneira ereta de uma cadeira sem os braços, curvar-se para pegar roupas no chão, fazer compras nas redondezas onde moram, entrar e sair de um ônibus, em afazeres domésticos, no lazer, entre outros. Todos conviviam com dores crônicas, e todos os aspectos encontrados envolvem significados e representações para os sujeitos, sofrendo influências também de aspectos culturais que envolvem o ser humano na sociedade, entre outros, e que podem agravar ou não os aspectos funcionais relacionados ao cotidiano de vida. Os aspectos encontrados podem gerar desgaste e sofrimento aos sujeitos que se vêm incapacitados de fazer atividades antes realizáveis, e por afetar os diversos papéis sociais desempenhados, entre outros, afetando também a saúde mental.

Este artigo evidencia que há aspectos físicos envolvendo a incapacidade, mas que a incapacidade deve ser compreendida de um modo mais complexo, envolvendo as relações entre as pessoas e o contexto social, uma vez que o desempenho de atividades é relacional.

Os sujeitos deste estudo adoeceram em plena fase produtiva, tinham baixa escolaridade, portanto há necessidade também de reflexões sobre as exigências do mundo do trabalho contemporâneo, e de ações constantes que visem à prevenção também com olhares mais abrangentes.

Sobre as intervenções em Terapia Ocupacional junto aos trabalhadores afastados do trabalho, orientações posturais podem ser realizadas para se evitar agravos e riscos de surgimento de sintomas nas tarefas do cotidiano de vida, mas são fundamentais também outras intervenções 
que auxiliem junto ao enfrentamento da situação, uma vez que a dor e o afastamento do trabalho podem provocar em geral insegurança, medo, sentimento de inutilidade, entre outros. São indicadas atividades expressivas, reflexivas, corporais, em grupos temáticos, entre outras, bem como intervenções interdisciplinares. Pesquisasfuturas devem investigar e aprofundar os aspectos aqui analisados, juntos aos trabalhadores afastados do trabalho por afecções lombares.

Alencar, M. C. B.; Terada, T. M. The retirement of work from low back diseases: repercussions on the [UTF-8?]subjectsâ€тM daily lifes. Rev. Ter. Ocup. Univ. São Paulo, v. 23, n. 1, p. 44-51, jan./abr. 2012.

\begin{abstract}
The objective of this study was to investigate aspects of the retirement of work from low back disease of subjects assisted in the stage of Occupational Therapy course of Federal University of Sao Paulo, and repercussions on subjects' daily life. It was used instrumentals, containing demographic data, related to work, clinical aspects, about how pain affected daily life, and others, and the instrument Health Assessment Questionnaire - HAQ, applied as an interview. Participated in this study eight $(n=8)$ subjects, age between 37 and 55 years old, four of each sex. All the subjects referred chronic low back pain, and others. The retirement of work and pain affected few of the daily life's activities and this study emphasizes the necessity of an embraced view about the incapacity.
\end{abstract}

KEYWORDS: Sick leave; Chronic pain; Occupational therapy, Activities of daily life.

\title{
4. REFERÊNCIAS
}

1. ALENCAR, M. C. B.; OTA, N. H. O afastamento do trabalho por LER/DORT: repercussões na saúde mental. Rev. Ter. Ocup. Univ. de São Paulo, v. 22, n. 1, p. 60-67, 2011.

2. FERRAZ, M. B.; OLIVEIRA, L. M.; ARAUJO, P. M. P.; ATRA, E.; TUGWELL, P. Crosscultural Reliability of the Physical Ability Dimension of the Health Assessment Questionnaire. J. Rheumatol., v. 17, p. 813-817, 1990.

3. GAEDKE, M. A.; KRUG, S. B. F. Quem sou eu? A identidade de trabalhadoras portadoras de LER/DORT. Rev. Textos Contextos, v. 7, n. 1, p. 120-137, 2008.

4. GHisleni, A. P.; MERLO, A. R. C. Trabalhador contemporâneo e patologias por hipersolicitação. Psicol. Reflexão Crítica, v. 18, n. 2. p. 171-176, 2005.

5. GOFFMAN, E. A representação do eu na vida cotidiana. Petrópolis: Vozes, 2009.

6. MÂNGIA, E. F.; MURAMOTO, M. T.; LANCMAN, S. Classificação Internacional de Funcionalidade, Incapacidade e Saúde (CIF): processo de elaboração e debate sobre a questão da incapacidade. Rev. Ter. Ocup. Univ. São Paulo, v. 19, n. 2, p. 121-130, 2008.

7. MEZIAT FILHO, N.; SILVA, G. A. Invalidez por dor nas costas entre segurados da Previdência Social do Brasil. Rev. Saúde Pública, v. 45, n. 3, p. 494-502, 2011.

8. MERLO, A. R. C.; JAQUES M. G. C.; HOEFEL, M. G. L.
Trabalho de grupo com portadores de LER/DORT: relato de experiência. Psicol. Reflexão Crítica, v. 14, n. 1, p. 253-258, 2001.

9. MERLO, A. R. C.; VAZ, M. A.; SPODE, C. B.; ELBERN, J. L. G.; KARKOW, A. R. M.; VIEIRA, P. R. B. O trabalho entre prazer, sofrimento e adoecimento: a realidade dos portadores de lesões por esforços repetitivos. Psicol. Sociedade, v. 15, n. 1, p. 117-136, 2003.

10. BRASIL. Ministério da Previdência e Assistência Social. Anuário Estatístico de Acidentes de Trabalho de 2009. Disponível em: <http:// www.mpas.gov.br/conteudoDinamico. php?id=989> . Acesso em novembro de 2011.

11. NEVES, R. F.; NUNES, M. O. Incapacidade, cotidiano e subjetividade: a narrativa de trabalhadores com LER/DORT. Interface: Comum. Saúde Educ., v. 13, n. 30, p. 55-56, 2009.

12. NEGRELLI, W. F. Hérnia discal: procedimentos de tratamento. Acta Ortop. Bras., v. 9, n. 1, p. 39-45, 2001.

13. PICOLOTO, D.; SILVEIRA, E. Prevalência de sintomas osteomusculares e fatores associados em trabalhadores de uma indústria metalúrgica de Canoas - RS. Ciên. Saúde Coletiva, v. 13, n. 2, p. 507-516, 2008.

14. POLIZETTI, K. M.; LEITE, S. N. Quem sente é a gente, mas é preciso revelar: a lombalgia na vida das trabalhadoras do setor têxtil de Blumenau - Santa Catarina. Saúde Sociedade, 
v. 19, n. 2, p. 405-417, 2010.

15. RAMOS, M. Z.; TITTONI, J.; NARDI, H. C. A experiência de afastamento do trabalho por adoecimento vivenciada como processo de ruptura ou continuidade nos modos de viver. Cad. Psicol. Trab., v. 11, n. 2, p. 209-221. 2008.

16. SARTRI, C.A. A dor, o indivíduo e a cultura. Saúde Sociedade, v. 10, n. 1, p. 3-13, 2001.

17. TAIT, R. C.; CHIBNALL, J. T.; KRAUSE, S. The pain disability index: psychometric properties. Pain, v. 40, p. 171182, 1990.

Recebido para publicação: 07/01/2011

Aceito para publicação: 29/03/2012
18. WADELL, G. Preventing incapacity in people with musculoskeletal disorders. Brit. Med. Bull., p.1-15, 2006. DOI: 10.109/bmb/ldl008.

19. WEINER, D. K.; RUD, T. E.; KIM, Y. S.; GOLLAS, S. Do medical factors predict disability in older adults with persistent low back pain? Pain, v. 112, n. 1, p. 214-220, 2004.

20. YENG, L. T.; TEIXEIRA, M. J; FERNANDES, M. M.; ZAKKA, T. R. M; LODUCA, A. Distúrbios osteomusculares relacionados ao trabalho. In: COSTA, O. C. Dor: princípios e práticas. São Paulo: Artmed, 2009. 